\title{
RF energy harvesting prototype operating on multiple frequency bands with advanced power management
}

\author{
Manee Sangaran Diagarajan, Agileswari Ramasamy, Navaamsini Boopalan, Norashidah Bt. Md Din \\ College of Post Graduate Studies, University Tenaga Nasional, Malaysia
}

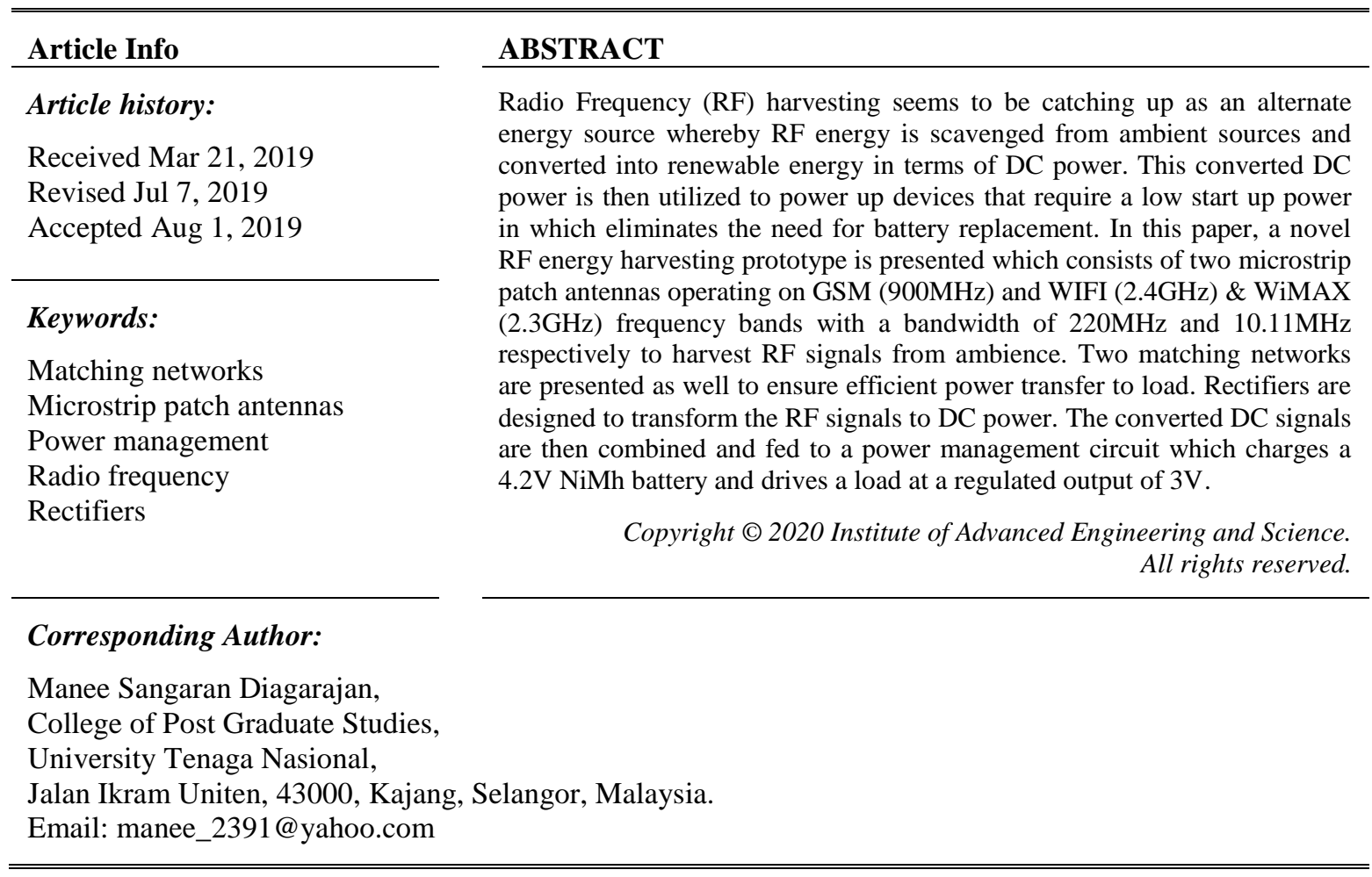

\section{INTRODUCTION}

In the recent times, various researches have been carried out regarding RF energy harvesting methods. The idea behind this harvesting method is to scavenge the RF energy received through ambience or dedicated sources and transform them into alternative power in the means of renewable energy [1-5]. This is made possible by designing an appropriate rectenna which consists of an antenna together with a rectifier to convert harvest RF and convert it into DC. This method of renewable energy is best applied in a wireless sensor network system. Wireless sensors are known to have a restricted lifetime due to its battery usage [6-9]. This is where a RF energy harvesting device can play a crucial part as a supportable power supply which replaces the need for batteries [10,11]. Some of the current applications where this has been implemented are related to wireless. This involves sensor networks [12], body networks [13] and charging systems [14]. Over the years, many advancements in terms of circuit design has been incorporated to come up with an efficient and optimized RF energy harvesting system to harvest as much as power available [15].

This paper intends to deliver a RF energy harvesting prototype which operates on GSM, WIFI \& WiMAX frequency bands. Two microstrip patch antennas were designed and tested under appropriate field conditions [16]. One antenna is operating on the GSM $900 \mathrm{MHz}$ band and the other is on dual band operation which is WiMAX 2.3GHz \& Wi-Fi 2.4GHz. Design and results of matching networks and rectifiers are also discussed in this paper. Lastly, a power management module is introduced via the BQ25570 IC to power up a low power device. 


\section{RESEARCH METHOD}

The summary of the RF energy harvesting prototype is depicted as the Figure 1. To harvest RF energy from the GSM $900 \mathrm{MHz}$ band, an E shaped microstrip patch antenna is designed, optimized and incorporated to the system. A dual band E shaped patch antenna with a partial ground plane as well is designed to harvest RF energy from WIFI $2.4 \mathrm{GHz}$ band and WiMAX 2.3GHz. Matching networks are introduced after the antenna to ensure efficient power transfer from the antenna to the rectifier [17]. The RF energy harvested is then fed into a 5 stage Villard voltage double circuit [18]. This circuit transforms the RF energy to DC. The converted DC power is then combined and fed into the power management circuit. The power management circuit consists of the BQ25570, a battery and a load. All the design and results of the mentioned components will be discussed in the next section.

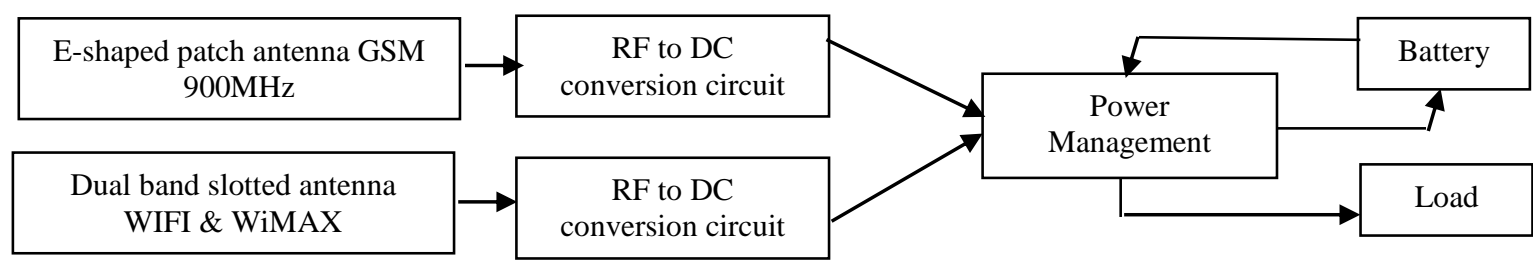

Figure 1. RF energy harvesting prototype

\section{RESULTS AND ANALYSIS}

The design of all the circuitry was done using Computer Simulation Technology (CST) software and was optimized to operate optimally before fabrication [19-25]. All circuitry was tested on appropriate field conditions and hardware optimization was done to achieve desired results. This section will discuss in detail the design and results of the microstrip patch antennas, matching networks, rectifier modules and the power management module.

\subsection{Microstrip Patch Antenna}

There are two types microstrip patch antenna designed for this work. One is the E shaped patch antenna which is designed to operate on GSM $900 \mathrm{MHz}$ and a dual band E shaped antenna which operates on WIFI $2.4 \mathrm{GHz}$ and WiMAX $2.3 \mathrm{GHz}$. Both the antennas have partial ground plane which benefits in increasing the operating bandwidth of the antenna. The transmission line is optimally placed to obtain the best return loss results $[23,24]$. The dimensions of the antennas were calculated based on the microstrip patch antenna equations and depicted Figure 2 and Figure 3 and Table 1 and Table 2.

Table 1. E Shaped Patch Antenna Dimensions

\begin{tabular}{llc}
\hline Component & Variable & Dimension $(\mathrm{mm})$ \\
\hline E-Shaped Patch & Width & 96 \\
Antenna & Length & 77 \\
& S1 Width & 2 \\
& L2 Width & 72 \\
& Length & 70 \\
Feed Line & Width & 3 \\
& Length & 27 \\
\hline \multicolumn{2}{c}{ *S1 \& S2 refers the slot on the patch antenna }
\end{tabular}

Table 2. Slotted Dual Band Antenna Dimensions

\begin{tabular}{cccc}
\hline Component & Variable & Dimension $(\mathrm{mm})$ \\
\hline E-Shaped Patch & Width & 38 \\
Antenna & Length & 28 \\
& Slot & Width & 1 \\
Feed Line & & Length & 10 \\
& & Width & 2 \\
& & Length & 14 \\
\hline
\end{tabular}




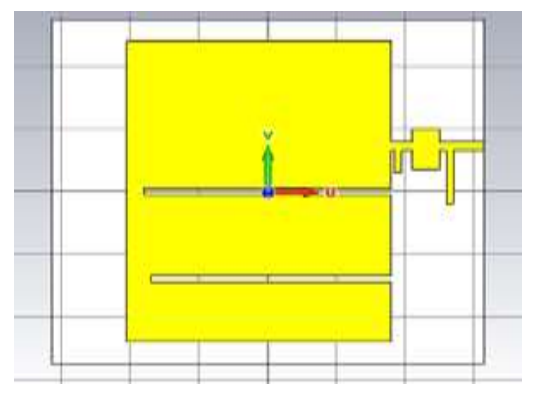

Figure 2. E shaped patch antenna design



Figure 3. E shaped dual band antenna design

Slots were introduced into the patch to create fringing effects to obtain better bandwidth and return loss. S parameters were calculated using CST and the results are displayed in Figure 4.

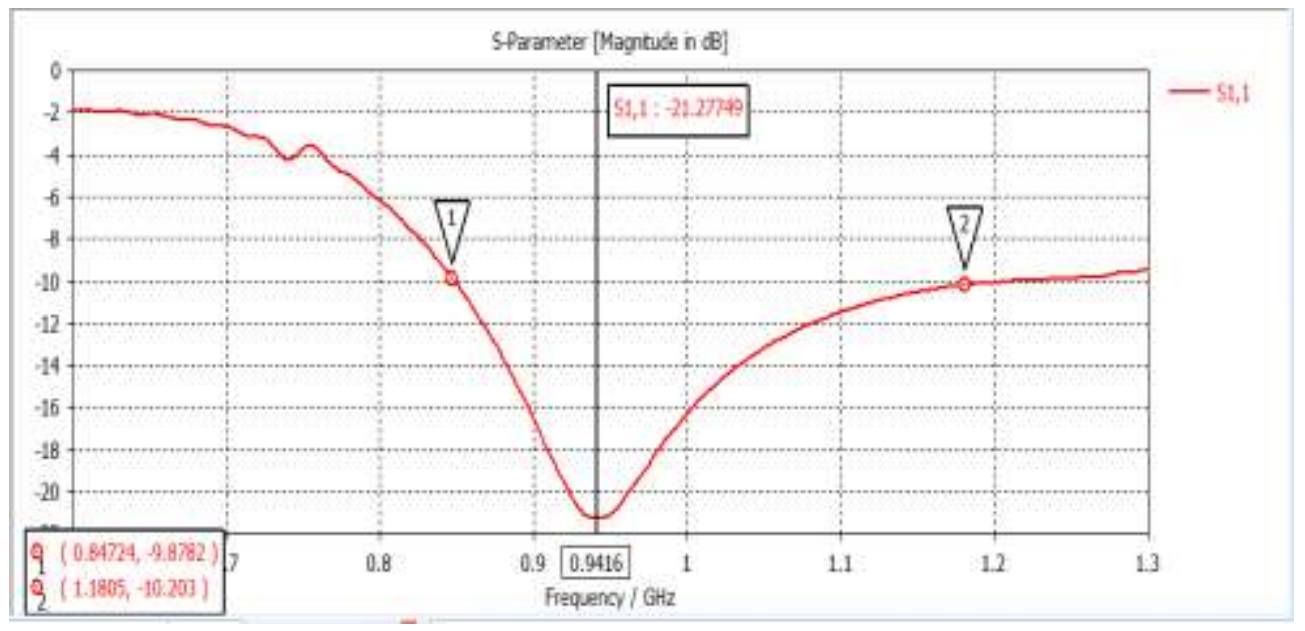

Figure 4. Return loss plot of GSM 900MHz patch antenna

The antenna was observed to be resonating at $941.6 \mathrm{MHz}$ with a wide bandwidth of $88.57 \mathrm{MHz}$. The return loss of the antenna was recorded to be at $-21.23 \mathrm{~dB}$.

The dual band patch antenna was observed to be resonating at $2.3 \mathrm{GHz}$ and $2.4 \mathrm{GHz}$ with a bandwidth of $10.11 \mathrm{MHz}$ and $9.78 \mathrm{MHz}$ respectively. Return loss of the antenna was recorded to be at $12.243 \mathrm{~dB}$ for WiMAX and $-12.345 \mathrm{~dB}$ for WIFI. Return loss plot of both patch antenna can be seen in Figure 5.

Both the antennas were tested using a transmitting antenna, as shown in Figure 6, which was fed by a signal generator. Distance and power level were recorded to observe the performance of the antenna. 




Figure 5. Return loss plot of WiMAX 2.3GHz and WIFI 2.4GHz patch antenna
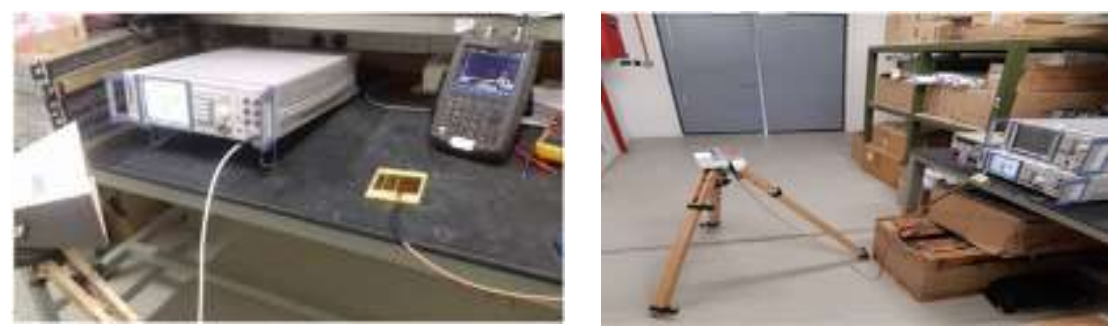

Figure 6. Testing of microstrip patch antennas via signal generator

Based on the testing conducted, it can be observed that the power level decreases as the antenna is moved further from the source which in this case is a signal generator. However, the power level on the GSM $900 \mathrm{MHz}$ patch antenna is compared to be better than the dual band slotted antenna. This is because the dual band antenna suffers path loss due to its higher frequency compared to the GSM 900 patch antenna [13-16]. The antennas were also tested near a cell tower and a wireless router. The same were observed when tested when a signal generator. Results are in Table 3.

Table 3. Antenna received power level tested on field

\begin{tabular}{llc}
\hline Component & Distance $(\mathrm{cm})$ & Received Power Level $(\mathrm{dBm})$ \\
\hline E- shaped patch antenna tested near a cell tower & 50 & -6 \\
& 100 & -11 \\
& 150 & -14 \\
& 200 & -20 \\
Dual band slotted antenna tested near wireless router & 250 & -25 \\
& 50 & -4 \\
& 100 & -9 \\
& 150 & -13 \\
& 200 & -19 \\
\hline
\end{tabular}

\subsection{Matching Network}

Impedance transformation is very important to enable maximum power transfer between a source and a load. The performance of the circuit is tuned to control the impedance of the source or load. The graphical method employing the Smith chart can be used to transform networks [17]. Such method is used in this research work via the ADS software. This work contains two matching networks, one for each antenna as they operate on different frequencies. The first matching network operating on the GSM band is designed with a source of $50 \mathrm{ohm}$ and a load of $77+\mathrm{j} 55$. The second matching network operating on the WiFI \& WiMAX band is designed with a source of 50ohm and a load of 58-j23. Figure 7 and 8 shows the return loss plot of the first and second matching network.

RF energy harvesting prototype operating on multiple frequency bands ... (Manee Sangaran Diagarajan) 


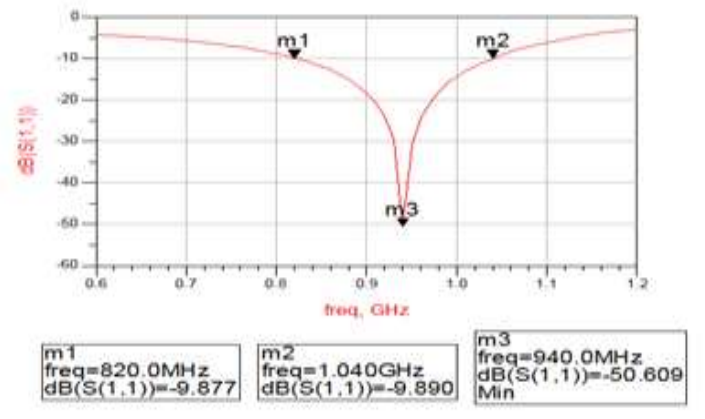

Figure 7. Return loss plot on GSM band



Figure 8. Return loss plot on WIFI \& WiMAX band

From the figure above, the matching networks are observed to be resonating at the desired frequency which is $940 \mathrm{MHz}$ and $2.4 \mathrm{GHz}$. The bandwidth of the matching network is $220 \mathrm{MHz}$ and the return loss of the matching network is recorded to be at $-50.609 \mathrm{~dB}$ for the GSM band. The bandwidth of the matching network is $100 \mathrm{MHz}$ and the return loss of the matching network is recorded to be at $-46.215 \mathrm{~dB}$ for the WiFi \& WiMAX band. Both the matching networks are designed based on lumped elements and added to the transmission lines of the antenna.

\subsection{Rectifier Module}

The RF to DC conversion circuit being employed for this research work is the Villard voltage doubler circuit. For simulation, the NI Multisim software is being used. The Agilent HSMS-280 diodes are chosen to be used in RF to DC conversion circuit. These diodes have a very low forward voltage which suits best in this application [18-20]. The number of stages of voltage doubler was studied during simulation and 5 -stage voltage doubler circuit is being implemented. The same rectifier module is used for both the patch antennas, however with different impedance matching circuits. A single stage of the voltage doubler circuit is shown in Figure 9 and the values for the components of the circuits are tabulated as shown in Table 4.

The circuit was tested by feeding a RF signal operating on $945 \mathrm{MHz}$ and $2.4 \mathrm{GHz}$. DC output was measured and tabulated in Table 5.

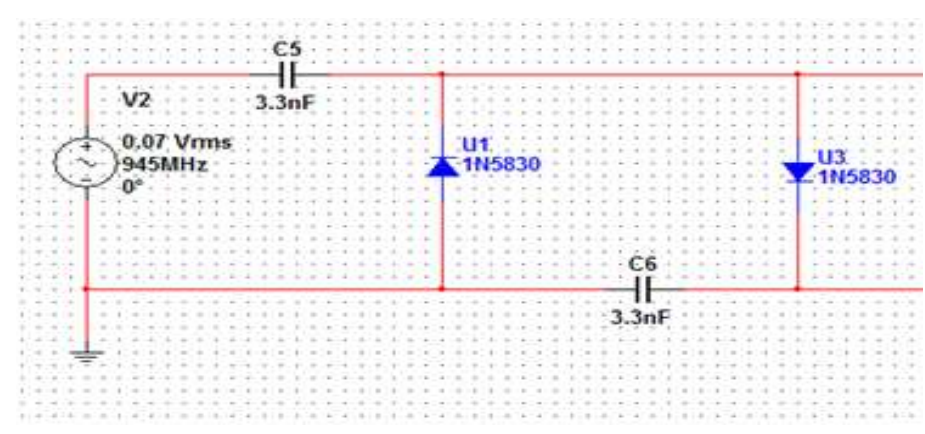

Figure 9. Single stage voltage doubler circuit

Table 4. Voltage doubler components

\begin{tabular}{ll}
\hline Component & Value \\
\hline Diodes & Agilent HSMS-280 \\
Stage Capacitor & $3.3 \mathrm{nF}$ \\
Filter Capacitor & $100 \mathrm{nF}$ \\
Load Resistor & $100 \mathrm{kohm}$ \\
\hline
\end{tabular}


Table 5. Voltage doubler results

\begin{tabular}{ccc}
\hline Input Power (dbm) & Voltage (V) GSM & Voltage (V) WiFI \& WiMAX \\
\hline-40 & 0.02 & 0.01 \\
-35 & 0.12 & 0.10 \\
-30 & 0.24 & 0.22 \\
-25 & 0.38 & 0.35 \\
-20 & 0.49 & 0.54 \\
-15 & 0.66 & 0.58 \\
-10 & 0.94 & 0.80 \\
-5 & 1.29 & 1.04 \\
0 & 2.97 & 2.51 \\
5 & 6.34 & 4.89 \\
\hline
\end{tabular}

\subsection{Power Management}

A power management circuit is introduced into the RF energy harvesting system to efficiently manage the converted DC power obtained from the rectifier. Here, the BQ25570 integrated chip from Texas Instruments is utilized for power management. The IC is designed to work well with high impedance sources such as RF signals. It also has a user programmable Maximum Point Tracking algorithm which ensures the input voltage doesn't fall below $80 \%$ of the previous open circuit voltage. This IC is programmed to have a regulated voltage output together with the capability of charging a rechargeable battery. In this work, the IC is programmed to have a regulated output of $3 \mathrm{~V}$ and connected with a $4.2 \mathrm{~V}$ NiMH rechargeable battery. This is done by varying the resistors on the IC. The rechargeable battery will be constantly charged by the IC if there is incoming power. In the case where there is no incoming power, the battery will kick in to power up the IC and still supply the $3 \mathrm{~V}$ regulated output. The cold start voltage requirement for the IC is at $330 \mathrm{mV}$ which is achievable from the rectenna system designed. Figure 10 shows an example of the E-shaped antenna with the rectifier connected to the BQ25570 IC. Output of the IC is connected to a battery and load.



Figure 10. BQ25570 circuitry with antenna and rectifier connected with battery and load

The rectenna supplies the required voltage for the BQ25570 to operate. From the testing, it was noticed that with a combined input of $330 \mathrm{mV}$, the BQ25570 took 125 seconds to start charging the battery at $4.2 \mathrm{~V}$. Once this happens, the output is measured to be at $3 \mathrm{~V}$. Now the input can be as low as $100 \mathrm{mV}$ to harvest and the battery charging and the output of $3 \mathrm{~V}$ would be still available. The TI HDC2010 low power sensor was connected as a load. The module was charged for 2 minutes and the incoming RF power was removed from the system. The system could run for 155 seconds and the $3 \mathrm{~V}$ output was still present. The storage element provides a constant power of $3 \mathrm{~V}$ to the system and ensures no interruption to load. The power management was tested with the rectenna and results are tabulated in Table 6.

Table 6. BQ25570 power management results

\begin{tabular}{ccc}
\hline DC Input $(\mathrm{V})$ & Time to start charging battery & Time to start regulated output \\
\hline 0.04 & N/A & N/A \\
0.1 & N/A & N/A \\
0.7 & 348 & 121 \\
1.4 & 273 & 258 \\
1.8 & 134 & 312 \\
\hline
\end{tabular}

RF energy harvesting prototype operating on multiple frequency bands ... (Manee Sangaran Diagarajan) 
At a distance of $1 \mathrm{~m}$ from a cell tower and a wireless router, the system could output a combined DC voltage of $2.5 \mathrm{~V}$. This DC voltage is enough to run the BQ25570 power management circuit. The BQ25570 provides a regulated output of $3 \mathrm{~V}$ which is connected to the TI HDC2010 low power humidity sensor. At the same time, the BQ25570 charges a $4.2 \mathrm{~V} \mathrm{NiMH}$ battery which can back up the system in case there is no RF incoming power.

\section{CONCLUSION}

A RF energy harvesting system operating on multiple frequency bands which includes the GSM, WIFI \& WiMAX band is presented. The objectives of the research have been met. Suitable rectifier modules and matching networks are designed to ensure optimized results are obtained. The BQ25570 has been integrated as a power management tool for the circuit. At $1 \mathrm{~m}$ from a cell tower and a wireless router, the system could output a combined DC voltage of $2.5 \mathrm{~V}$. This DC voltage is enough to run the BQ25570 power management circuit. The BQ25570 provides a regulated output of 3V which is connected to the TI HDC2010 low power humidity sensor. At the same time, the BQ25570 charges a 4.2V NiMh battery which can back up the system in case there is no RF incoming power.

\section{ACKNOWLEDGEMENTS} 03-SF0291).

This work is supported by the Ministry of Science, Technology and Innovation Malaysia (no.03-02-

\section{REFERENCES}

[1] Le, T.; Mayaram, K.; Fiez, T., "Efficient Far-Field Radio Frequency Energy Harvesting for Passively Powered Sensor Networks," Solid-State Circuits, IEEE Journal of , vol.43,

[2] Dolgov, A.; Zane, R.; Popovic, Z., "Power Management System for Online Low Power RF Energy Harvesting Optimization," Circuits and Systems I: Regular Papers, IEEE Transactions on, vol.57, no.7, pp.1802,1811, July 2010

[3] W. Brown, "Experiments in the transportation of energy by microwave beam," IRE Int. Convention Record, vol. 12, no. 2, pp. 8-17, 1964.

[4] Goyal, R.; Jain, Y.K., "Compact bow shape microstrip patch antenna with different substrates," Information \& Communication Technologies (ICT), 2013 IEEE Conference on , vol., no., pp.64,69, 11-12 April 2011

[5] Pinuela, M.; Mitcheson, P.D.; Lucyszyn, S., "Ambient RF Energy Harvesting in Urban and Semi-Urban Environments," in Proc. Microwave Theory and Techniques, IEEE Transactions, Asia Pacific on, vol.61, no.7, pp.2715,2726, July2013

[6] H. J. Visser and R. J. M. Vullers, "RF energy harvesting and transport for wireless sensor network applications: principles and requirements," Proceedings of the IEEE, vol. 101, no. 6, pp. 1410-1423, June 2013.

[7] Weigand, S.; Huff, G.H.; Pan, K.H.; Bernhard, J.T., "Analysis and design of broad-band single-layer rectangular Uslot microstrip patch antennas," Antennas and Propagation, IEEE Transactions on , vol.51, no.3, pp.457,468, March 2003

[8] Jayanthy, T.; Sugadev, M.; Ismaeel, J.M.; Jegan, G., "Design and simulation of Microstrip M-patch antenna with double layer," Recent Advances in Microwave Theory and Applications, 2008. MICROWAVE 2008. International Conference on , vol., no., pp.230,232, 21-24 Nov. 2008

[9] C. Mikeka and H. Arai, "Design issues in radio frequency energy harvesting system," Sustainable Energy Harvesting Technologies - Past, Present and Future, December 2011.

[10] Qiang Hu; Hai Lin; He-lin Yang; Nan Wu, "A novel slotted broadband microstrip patch antenna," Microwave, Antenna, Propagation, and EMC Technologies for Wireless Communications (MAPE), 2011 IEEE 4th International Symposium on , vol., no., pp.57,60, 1-3 Nov. 2011

[11] K. Huang and V. K. N. Lau, "Enabling wireless power transfer in cellular networks: architecture, modeling and deployment," IEEE Transactions on Wireless Communications, vol 13, no. 2, pp. 902-912, Feb. 2014.

[12] H. Nishimoto, Y. Kawahara, and T. Asami, "Prototype implementation of ambient RF energy harvesting wireless sensor networks," in Proceedings of IEEE Sensors, Kona, HI, November 2010.

[13] X. Zhang, H. Jiang, L. Zhang, C. Zhang, Z. Wang, and X. Chen, "An energy-efficient ASIC for wireless body sensor networks in medical applications," IEEE Transactions on Biomedical Circuits and Systems, vol. 4, no. 1, pp. 11-18, Feb. 2010.

[14] H. J. Visser and R. J. M. Vullers, "RF energy harvesting and transport for wireless sensor network applications: principles and requirements," Proceedings of the IEEE, vol. 101, no. 6, pp. 1410-1423, June 2013.

[15] Weigand, S.; Huff, G.H.; Pan, K.H.; Bernhard, J.T., "Analysis and design of broad-band single-layer rectangular Uslot microstrip patch antennas," Antennas and Propagation, IEEE Transactions on , vol.51, no.3, pp.457,468, March 2003 
[16] Y Iliyasu, Adamu. (2019). "Wideband frequency reconfigurable metamaterial antenna employing SRR and CSRR for WLAN application”. Indonesian Journal of Electrical Engineering and Computer Science (IJEECS). Vol 15 1436-1422. 10.11591/ijeecs. v15.i3. pp1436-1442

[17] Jayanthy, T.; Sugadev, M.; Ismaeel, J.M.; Jegan, G., "Design and simulation of Microstrip M-patch antenna with double layer," Recent Advances in Microwave Theory and Applications, 2008. MICROWAVE 2008. International Conference on , vol., no., pp.230,232, 21-24 Nov. 2008

[18] Farinholt, Kevin M.; Park, G.; Farrar, C.R., "RF Energy Transmission for a Low-Power Wireless Impedance Sensor Node," Sensors Journal, IEEE, vol.9, no.7, pp.793,800, July 2009

[19] C. Mikeka and H. Arai, "Design issues in radio frequency energy harvesting system," Sustainable Energy Harvesting Technologies - Past, Present and Future, December 2011.

[20] Munir, A.; Petrus, G.; Nusantara, H., "Multiple slots technique for bandwidth enhancement of microstrip rectangular patch antenna," QiR (Quality in Research), 2013 International Conference on , vol., no., pp.150,154, 25-28 June 2013

[21] Qiang Hu; Hai Lin; He-lin Yang; Nan Wu, "A novel slotted broadband microstrip patch antenna," Microwave, Antenna, Propagation, and EMC Technologies for Wireless Communications (MAPE), 2011 IEEE 4th International Symposium on, vol., no., pp.57,60, 1-3 Nov. 2011

[22] K. Huang and V. K. N. Lau, "Enabling wireless power transfer in cellular networks: architecture, modeling and deployment," IEEE Transactions on Wireless Communications, vol 13, no. 2, pp. 902-912, Feb. 2014.

[23] T. Ume, H. Yoshida, S. Sikine, Y. Fujita, T. Suzuki, and S. Otaka, "A 950-MHz rectifier circuit for sensor network tags with 10-m distance," IEEE J. Solid-State Circuits, vol. 41, no. 1, pp. 35-41, Jan. 2006.

[24] Xudong Wang; Zhengming Zhao; Guanhua Chen; Fanbo He, "RF energy harvesting with broadband antenna," Transportation Electrification Asia-Pacific (ITEC Asia-Pacific), 2014 IEEE Conference and Expo, vol., no., pp.1,5, Aug. 31 2014-Sept. 32014

[25] C. A. Balanis, Antenna theory: analysis and design, John Wiley \& Sons, 2012.

\section{BIOGRAPHIES OF AUTHORS}

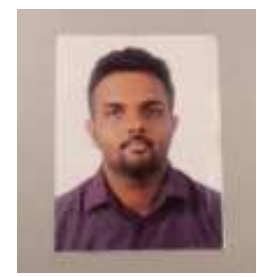

Manee Sangaran A/L Diagarajan. Completed his Degree in Electrical \& Electronics Engineering Hons in University Tenaga Nasional, Malaysia in the year of 2008. Currently pursuing his PhD in Engineering in University Tenaga Nasional as well.



Assoc. Prof. Ir. Dr. Agileswari Ramasamy. Completed her Degree in Engineering in Purdue University, USA in the year of 2001. Later, proceeded to complete her MSc. (Control System) from Imperial College, London in the year of 2001 and received her $\mathrm{PhD}$ in Engineering with University Tenaga Nasional. Currently she is serving as a Deputy Dean of Research and Post Graduate for College of Engineering, Uniten.



Navaamsini Boopalan. Completed her Bachelor Degree in Electrical and Electronic Engineering with University Tenaga Nasional (UNITEN) in year 2012. She joined Silterra Malaysia as Engineer in the same year. From year 2014 to now she is attached to Department of Communication Engineering, UNITEN as Research Officer. Meanwhile, she pursued and obtained her M.Eng in Electrical Engineering from UNITEN in 2017. Her research interests center around optimization and signal and systems.

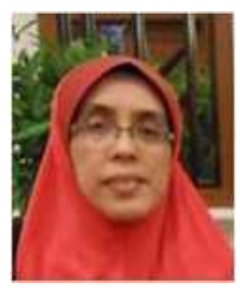

Dato' Prof. Ir. Dr., Dato' Norashidah Md Din. Completed her Degree in Electrical Engineering in Memphis State University, USA in the year of 1985. Later, proceeded to complete her M.S from Universiti Teknologi Malaysia (UTM) in the year of 1989 and received her PhD in Engineering with UTM as well in 2007. Currently she is serving as a Dean of College of Post Graduate Studies, Uniten. 